\title{
Histopathological and electron microscopy studies on sleepy disease of koi Cyprinus carpio koi in Japan
}

\author{
Teruo Miyazaki*, Tadashi Isshiki, Hori Katsuyuki \\ Faculty of Bioresources, Mie University, 1577 Kamihama, Tsu, Mie 514-8507, Japan
}

\begin{abstract}
Koi sleepy disease (KSD) usually occurs when koi Cyprinus carpio koi are taken from nursing earthen ponds and placed in cement-lined ponds containing fresh water in spring and autumn in Japan. We transfered koi from an earthen pond to tanks containing fresh water and $0.5 \%$ salt water in an attempt to replicate KSD and prevent the onset of KSD, respectively, in the laboratory. KSD broke out after 4 to 5 d, followed by mass mortality ( $76 \%$ : 95/125 fish) within $17 \mathrm{~d}$, in the fresh water. Diseased fish died within a few days. Examination revealed enlarged cells in the respiratory epithelia of gill lamellae; hyperplasia of interlammellar epithelia resulted in clubbing of gill filaments, which caused hypoxia when severe. Electron microscopy showed that enlarged cells contained immature particles (416-450 nm diameter) or mature virions (333-400 $\times 400-413 \mathrm{~nm})$ of a pox-like virus in the cytoplasm. Mature virions were transported to the periphery of the cells. Hepatocytes, renal tubular epithelial cells, muscle cells of the lateral musculature and cardiac muscle cells were cloudy with mitochondrial degeneration. PCR assay using primer sets for a pox-like virus causing 'carp edema' determined that KSD-virus is the same as the carp edema virus. None of the koi held in $0.5 \%$ salt water showed sleepy disease during a $25 \mathrm{~d}$ experimental period; PCR assay revealed no KSD-virus in gills of koi in the same treatment.
\end{abstract}

KEY WORDS: Koi · Cyprinus carpio koi · Koi sleepy disease · Pox-like virus · Carp edema virus · Respiratory epithelial cells · Clubbed gill filament · Hypoxia $\cdot$ Kinetic disturbance

\section{INTRODUCTION}

Japanese color carp (a strain of Cyprinus carpio) are known world-wide as koi. In Japan, cultured koi are usually held in cement-lined ponds containing fresh water to pass the winter after being moved from nursing earthen ponds with extensive blooms of phytoplankton. In this way, commercially valuable fish are selected. In the spring and autumn, many fish develop Koi sleepy disease (KSD). They lie on the bottom of clean-water ponds and die in a few days, causing mass mortality within the following $2 \mathrm{wk}$. An outbreak of KSD depends on the water temperature; the disease occurs within the range 15 to $25^{\circ} \mathrm{C}$, and it has been known since the mid-1970s. Diseased fish usually present with swollen gills, due to clubbing of gill filaments, while any parasites and bacteria are absent from the gills.

Koi farmers understand that a $0.5 \%$ salt-water bath is efficacious in preventing an outbreak of KSD. In recent years, koi farmers have held all fish in $0.5 \%$ salt water just after transportation from earthen ponds for prevention of KSD.

In the present study, we replicated KSD in the laboratory. The onset of KSD was observed, and features of diseased koi were revealed by histopathology, electron microscopy and PCR. Koi suffering from KSD displayed very similar external signs-lethargic movement, skin erosion and sunken eyes, and histopathological signs such as clubbed gill filaments - to those caused by koi herpesvirus disease (Hedrick et al. 2000). Therefore, reporting KSD is worthwhile to distinguish between these 2 viral diseases of koi.

\section{MATERIALS AND METHODS}

Koi. A total of 225 koi (1 yr old, 20 to $30 \mathrm{~g}$ ) were transferred to the laboratory at Mie University from an 
earthen pond in October 2001. We kept 125 fish in a tank containing $500 \mathrm{l}$ of fresh water with aeration to await onset of KSD. A pellet diet was given once daily and half of the water was exchanged every 3 or $4 \mathrm{~d}$ over a $25 \mathrm{~d}$ experimental period at 22 to $24^{\circ} \mathrm{C}$. Moribund fish showing symptoms and fish just after death were removed for examination. On the last day of the experiment, 5 of the surviving fish were collected. The other 100 fish were held in a tank containing $500 \mathrm{l}$ of $0.5 \%$ salt water with aeration in an attempt to prevent an outbreak of KSD. A pellet diet was given every day and most of the salt water was renewed once a week over a $25 \mathrm{~d}$ experimental period at 22 to $24^{\circ} \mathrm{C}$. Because no fish showed symptoms of KSD in this treatment, 5 fish were taken out for examination on the last day.

Histopathological examinations and electron microscopy. Moribund koi showing KSD symptoms and fish just after death (total 95 fish) were collected from the clean-water treatment. After external and internal observation of 73 moribund fish, tissue from the gills, visceral organs (including the heart, liver, spleen, kidney and intestine), the erosive skin and the lateral musculature were fixed in $10 \%$ buffered formalin. Ten heads, including sunken eyes, were fixed in Bouin's fluid. These samples were processed for histological examination according to standard methods. Gill tissue, liver, kidney and the lateral musculature of 28 of 73 moribund fish were fixed in $70 \%$ Karnovsky's solution and postfixed in $1 \% \mathrm{OsO}_{4}$ for electron microscopy. Remaining gill tissue, liver, kidney and skin lesions were stored at $-80^{\circ} \mathrm{C}$ for PCR assay.

From the $0.5 \%$ salt-water treatment, 5 surviving fish were collected on Day 25 and gill tissue, visceral organs, skin and musculature were histologically examined. Remaining gill tissue was stored at $-80^{\circ} \mathrm{C}$ for PCR assay.

PCR assay. Because electron microscopy revealed infection of a pox-like virus in epithelial cells of gill lamellae from diseased fish, primer sets for carp edema virus (CEV) (Oyamatsu et al. 1997b) were provided. PCR analysis using a primer set of CEV-F1 and CEV-R1 produces a DNA fragment sized 548 bp. Nested PCR analysis using a primer set of CEV-F2 and CEV-R2 produces a DNA fragment sized $181 \mathrm{bp}$. PCR analysis and nested PCR analysis were performed according to Oyamatsu et al. (1997b). The PCR assay was performed on tissue (stored at $-80^{\circ} \mathrm{C}$ ) - gills, skin, liver and kidney - of moribund fish, and on gills of surviving fish from the $0.5 \%$ salt water, while no positive control of CEV was provided in this study.

\section{RESULTS}

\section{Mortality}

Among koi in the clean-water treatment, diseased fish showing lethargy and 'sleepy' behavior appeared on Day 3. On Day 4, most of the fish showed sleepy behavior, but could swim momentarily after physical stimulation such as a body-touch with a stick. Several fish became moribund and died on Day 6 after losing a reaction to physical stimulation. Mass mortality occurred between Day 7 and Day 10, peaking on Day 8 (Fig. 1). Fish continued to die until Day 17, resulting in a $76 \%$ cumulative mortality (95/125 fish): 30 fish survived to the end of the experiment (Day 25). Most of the moribund fish and fish just after death displayed loss of skin mucus, epidermal erosion following partial ulceration, dermal anasarca and hemorrhage. Diseased fish often showed sunken eyes with hemorrhage (Fig. 2A). All gills were markedly swollen, due to epithelial hyperplasia of gill filaments (Fig. 2B). Muscle cells in the lateral musculature were cloudy with milky-white coloration. Moribund fish in particular, in the early period (6 to $7 \mathrm{~d}$ ), produced blood with a slight brown coloration, indicating the onset of methemoglobinemia. Surviving fish showed none of the external signs, except for slightly swollen gills.

Among koi in the $0.5 \%$ salt water, no diseased fish and no dead fish were found by the end of experiment (Day 25).

\section{Features of histopathology and electron microscopy}

Gills. The most obvious changes occurred in the gills, and the histopathological features were different

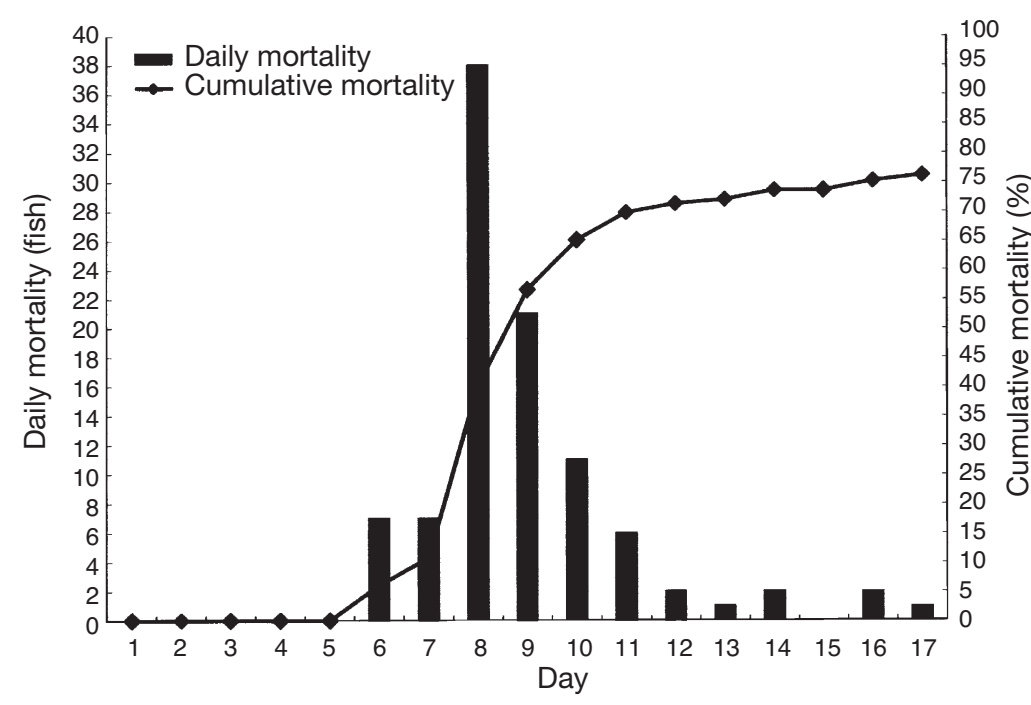

Fig. 1. Cyprinus carpio koi. Daily and cumulative mortalities of koi held in fresh water in an attempt to replicate KSD 

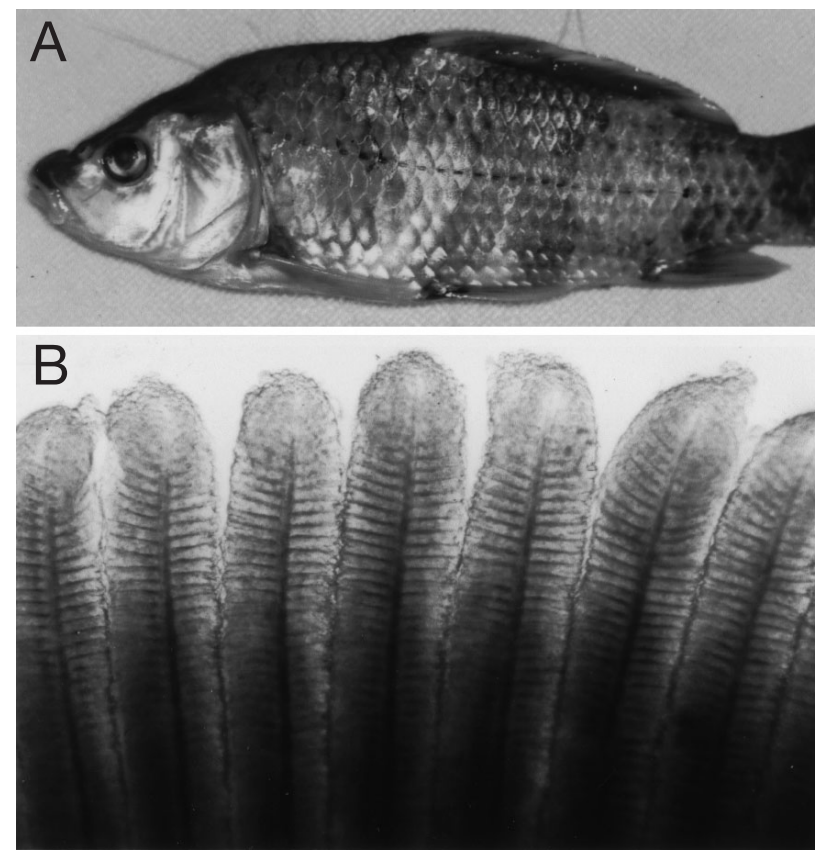

Fig. 2. Cyprinus carpio koi. (A) Diseased koi showing slightly sunken eyes with hemorrhage and erosive and ulcerative skin. (B) Gill filaments showing clubbing in moribund koi

in the early period ( 6 to $7 \mathrm{~d}$ : before a peak in mortality) from the later period ( 8 to $17 \mathrm{~d}$ : a peak in mortality and subsequent days).

In moribund fish from the early period, gill lamellae showed many enlarged cells in respiratory epithelia; interlamellar epithelial cells were proliferated, resulting in fusion of neighboring lamellae (Fig. 3A). The thickened interlamellar epithelia contained enlarged cells at the outermost layer and were infiltrated by many eosinophilic granular cells. Most of the enlarged cells showed marginal chromatosis of the nucleus (Fig. 3B) and were sometimes necrotic.

In moribund fish from the later period, hyperplasia of interlamellar epithelial cells extended to the tips of lamellae, resulting in clubbing of gill filaments (Fig. 3C). Fewer enlarged cells were left at the tips of lamellae, while the outermost layer of hyperplastic epithelia was extensively replaced by flattened cells. Interlamellar epithelia were infiltrated by many eosinophilic granular cells (Fig. 3D). In clubbed gill filaments, lamellar capillaries did not show any damage such as hemorrhage. In basal regions of gill filaments, proliferation of interlamellar epithelial cells was slight, and many enlarged cells were found in respiratory epithelia of lamellae.

In fish from the early period, electron microscopy (EM) of enlarged cells in the respiratory epithelia revealed many round, immature viral particles, and some maturing virions with an irregularly round shape in the cytoplasm. The cytoplasm was enlarged and also contained many glycogen particles, ribosomes, mitochondria, reticula, and Golgi apparatuses releasing many small vesicles and inclusions (Fig. 4A,B); in uninfected cells, these organelles were small in number and the Golgi apparatus in particular was rarely seen. The nucleus was enlarged with marginal chromatosis. These features of intracytoplasmic organelles and the nucleus indicate that virus-infected cells were hypertrophied. Additionally, infected cells had fine desmosomes, preventing separation from neighboring cells.

Early stage immature particles had a thin surface membrane without surface units, and the underlying core membrane enclosed a granular core (416-450 nm diameter). Some immature particles had a condensed, electron-dense core surrounded by a thickened core membrane. Immature particles were assembled beside inclusions consisting of fine granules (Fig. 4C). Double membranous structures with a crescent-shape were sometimes found on the inclusions (Fig. 4C inset). Maturing virions - found close to a Golgi apparatus releasing many vesicles-had a surface membrane partially worn with globular units and a core with high electron density (Fig. 4D).

In fish from the later period, EM revealed hypertrophied cells containing many mature virions within the cytoplasm not only in the upper layer of hyperplastic epithelia of clubbed gill filaments (Fig. 5A) but also in respiratory epithelia of gill lamellae (Fig. 5B). These cells also contained normal-looking mitochondria, some of which were degenerated, and Golgi apparatuses, slightly expanded reticula, pleomorphic inclusions and an enlarged nucleus.

Mature virions were ovoid but pleomorphic (333-400× 400-413 nm) and had a surface membrane worn by surface tubular units (50 $\mathrm{nm}$ in diameter), and a thickened core membrane enclosing an electron-dense, dumbbell-shaped core and a lateral body with an unclear outline at the invaginated point (Fig. 5C). Mature virions were transported to the periphery of the cells where they were associated with Golgi apparatuses, although there was no evidence that virions acquired a Golgi-derived envelope.

Some hypertrophied cells had a highly vacuolated cytoplasm and a degenerated nucleus; some contained a small number of immature particles in addition to mature virons. No viral particles were observed in flattened cells in the outermost layer and in interlamellar epithelial cells in the basal region of clubbed gill filaments (Fig. 5D). Many granular cells were infiltrated in hyperplastic interlamelar epithelia.

Liver. In the early period, the liver of moribund fish had many hepatocytes showing cloudy swelling (Fig. 6A). In these, EM revealed many mitochondria 


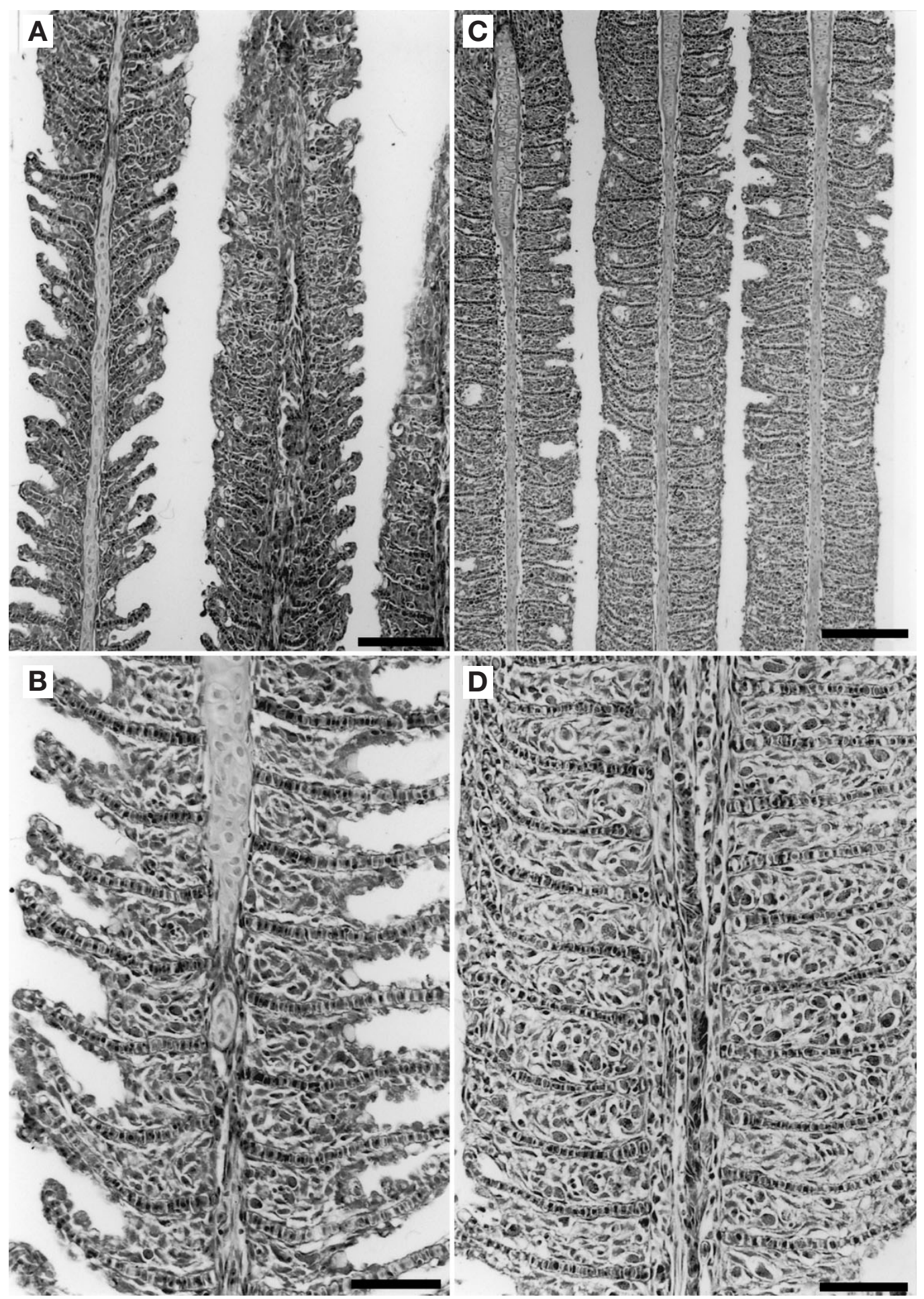

Fig. 3. Cyprinus carpio koi. (A,B) Gills of moribund koi from the early period (6 to 7 d: before a peak in mortality). (A) Gill filaments displaying many enlarged cells in respiratory epithelia of lamellae and lamellar fusion due to hyperplasia of interlamellar epithelial cells. Hematoxylin-Eosin stain (H\&E). Scale bar $=100 \mu \mathrm{m}$. (B) Detail of a gill filament. Respiratory epithelia of lamellae exhibit many enlarged cells. H\&E. Scale bar $=50 \mu \mathrm{m}$. (C,D) Gills of moribund koi from the later period ( 8 to $17 \mathrm{~d}$ : a peak in mortality and subsequent days). (C) Gill filaments show severe clubbing due to compensatory proliferation of interlamellar epithelial cells. Some lamellae have enlarged cells at the tips. H\&E. Scale bar $=100 \mu \mathrm{m}$. (D) Detail of clubbed gill filament. Interlamellar epithelia show hyperplasia of epithelial cells followed by infiltration of eosinophilic granular cells and replacement of flattenned cells in the topmost layer. H\&E. Scale bar $=50 \mu \mathrm{m}$ 

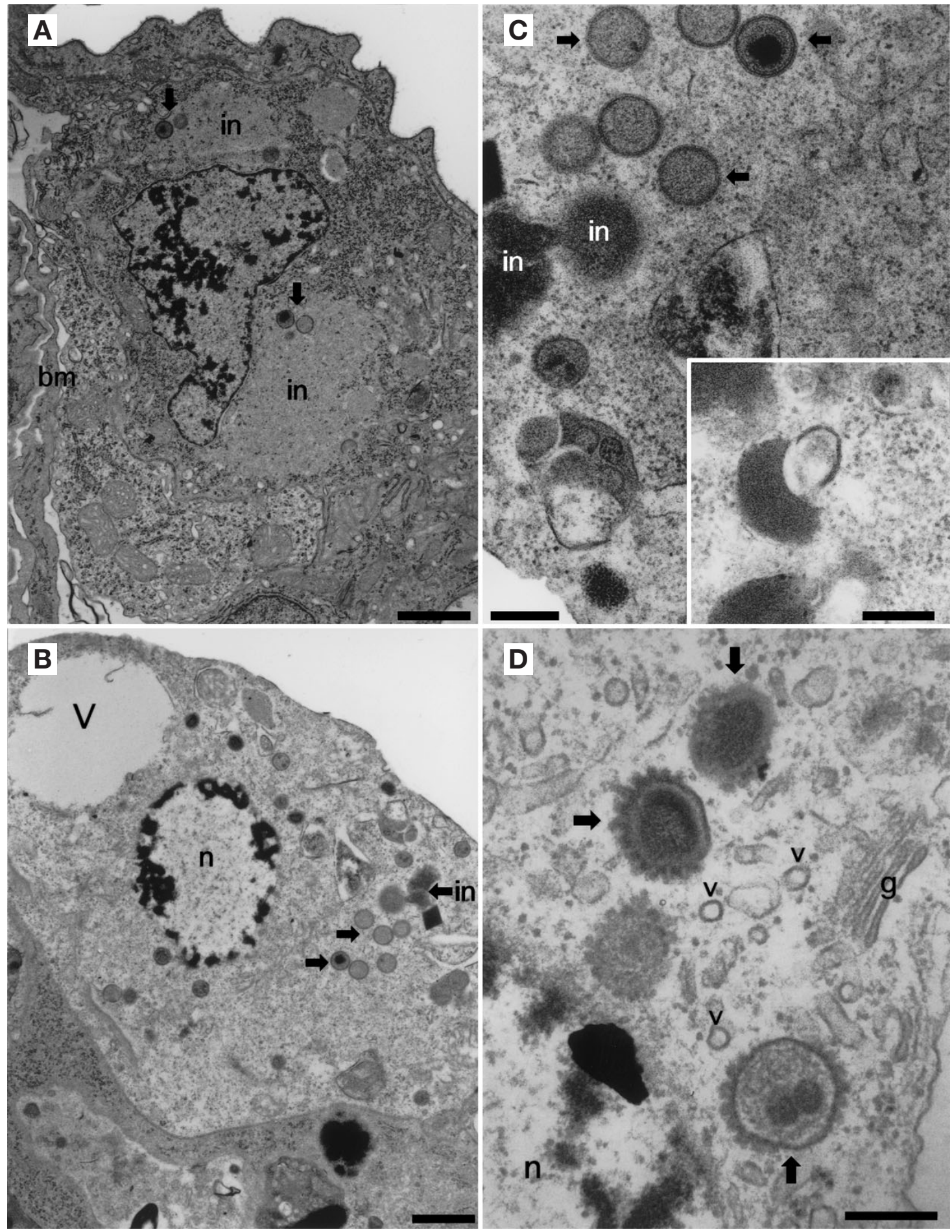

Fig. 4. Cyprinus carpio koi. (A,D) Electron micrographs of hypertrophic cells in the respiratory epithelia of moribund fish from the early period. (A) Hypertrophic cell showing immature virus particles within inclusions. Scale bar $=1660 \mathrm{~nm}$. (B) Hypertrophic cell showing many immature virus particles beside inclusions. Scale bar $=1350 \mathrm{~nm}$. (C) High-power view of immature particles beside inclusions. The early stage immature particles have a thin surface membrane and an underlying core membrane enclosing a granular core. Immature particles have a condensed, electron-dense core surrounded by a thickened core membrane. Scale bar = $450 \mathrm{~nm}$. (inset) Double membranous structures with a crescent-shape formed on an inclusion. Scale bar $=120 \mathrm{~nm}$. (D) Maturing virions showing a surface membrane partially worn with globular units and a core with high electron density. These maturing virions are located close to a Golgi apparatus releasing many small vesicles. Scale bar $=300 \mathrm{~nm}$. Arrows: virus particles; bm: basal membrane of lamellar capillary; g: Golgi apparatus; in: inclusion; n: nucleus of hypertrophic cells; V: vacuole; v: vesicle 

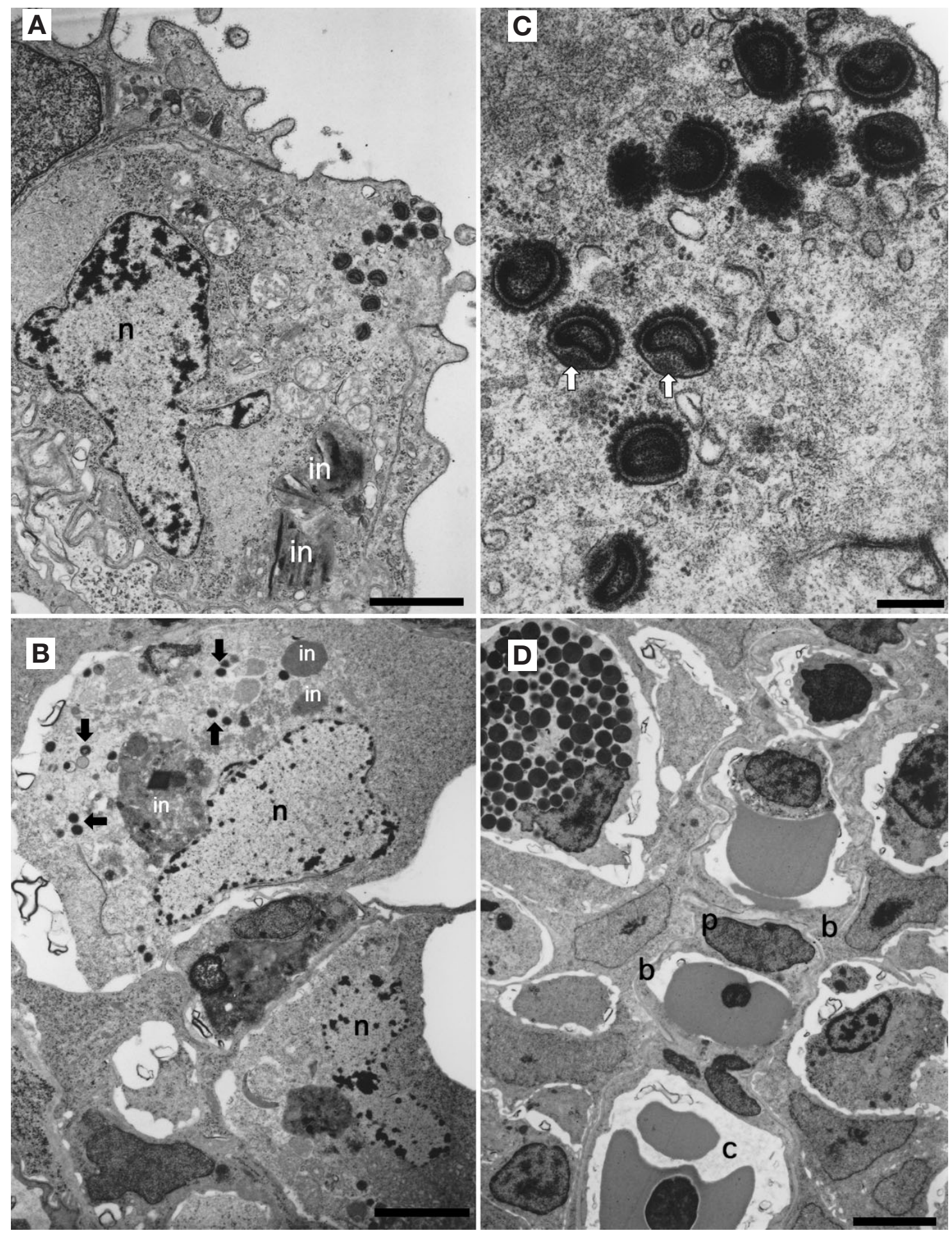

Fig. 5. Cyprinus carpio koi. (A,C) Electron micrographs of hypertrophic cells of moribund fish from the later period. (A) Hypertrophic cell in thickened interlamellar epithelium. Mature virions are transported to the periphery of the cell. Scale bar $=1700 \mathrm{~nm}$. (B) Hypertrophic cells in the respiratory epithelium. Upper cell contains many mature virions. Scale bar $=3000 \mathrm{~nm}$. (C) Highpower view of mature virions. Virions have a surface membrane entirely worn by surface globular units and a thickened core membrane enclosing an electron-dense core. A lateral body (white arrows) with an unsharp outline is present beside the core. Scale bar $=350 \mathrm{~nm}$. (D) Basal region of clubbed gill filament. Cells in this region are spared KSDV infection and granular cells are infiltrated among them. Scale bar $=4800 \mathrm{~nm}$. Black arrows: virus particles; b: basal membrane of lamellar capillary; c: lamellar 

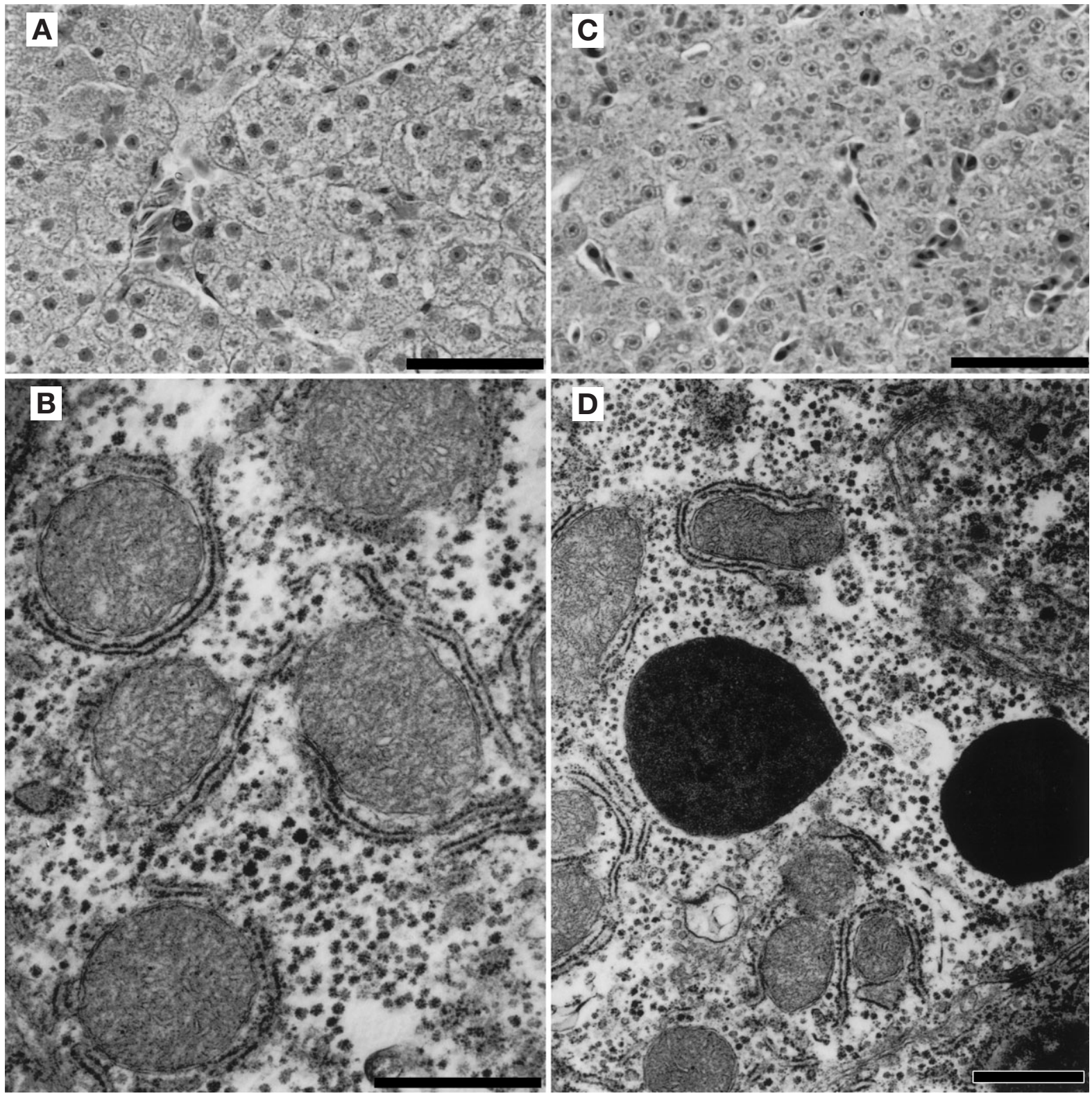

Fig. 6. Cyprinus carpio koi. (A,B) Liver of moribund fish from the early period. (A) All hepatocytes display cloudy swelling. H\&E. Scale bar $=200 \mu \mathrm{m}$. (B) Electron micrograph of hepatocyte showing cloudy swelling. Many mitochondria are degenerated showing damaged cristae and membranes. Scale bar $=1000 \mathrm{~nm}$. (C,D) Liver of moribund fish at the latter period. (C) Many hapatocytes showed hyaline droplet degeneration. H\&E. Scale bar $=200 \mu \mathrm{m}$. (D) Electron micrograph of hepatocyte showing hyaline droplets. Mitochondria are degenerated and occupied with electron-dense matter. Scale bar $=1000 \mathrm{~nm}$

that were markedly swollen and rounded with damaged cristae (Fig. 6B), which appeared as fine eosinophilic granules in light microscopy. Sinusoids and blood vessels contained erythrocytes with darkbrown cytoplasm, which indicated the presence of methemoglobin.

In the liver of moribund fish from the later period, many hapatocytes exhibited hyaline droplet degeneration and vacuolization, as well as cloudy swelling
(Fig. 6C). EM of hepatocytes with hyaline droplet degeneration revealed many electron-dense bodies derived from damaged mitochondria, as well as degenerated mitochondria (Fig. 6D).

Kidney. Renal tubular epithelial cells showed cloudy swelling and hyaline droplet degeneration (Fig. 7A). Hyaline droplet degeneration was marked in moribund fish from the later period. EM of these cells revealed many pleomorphic, electron-dense bodies 

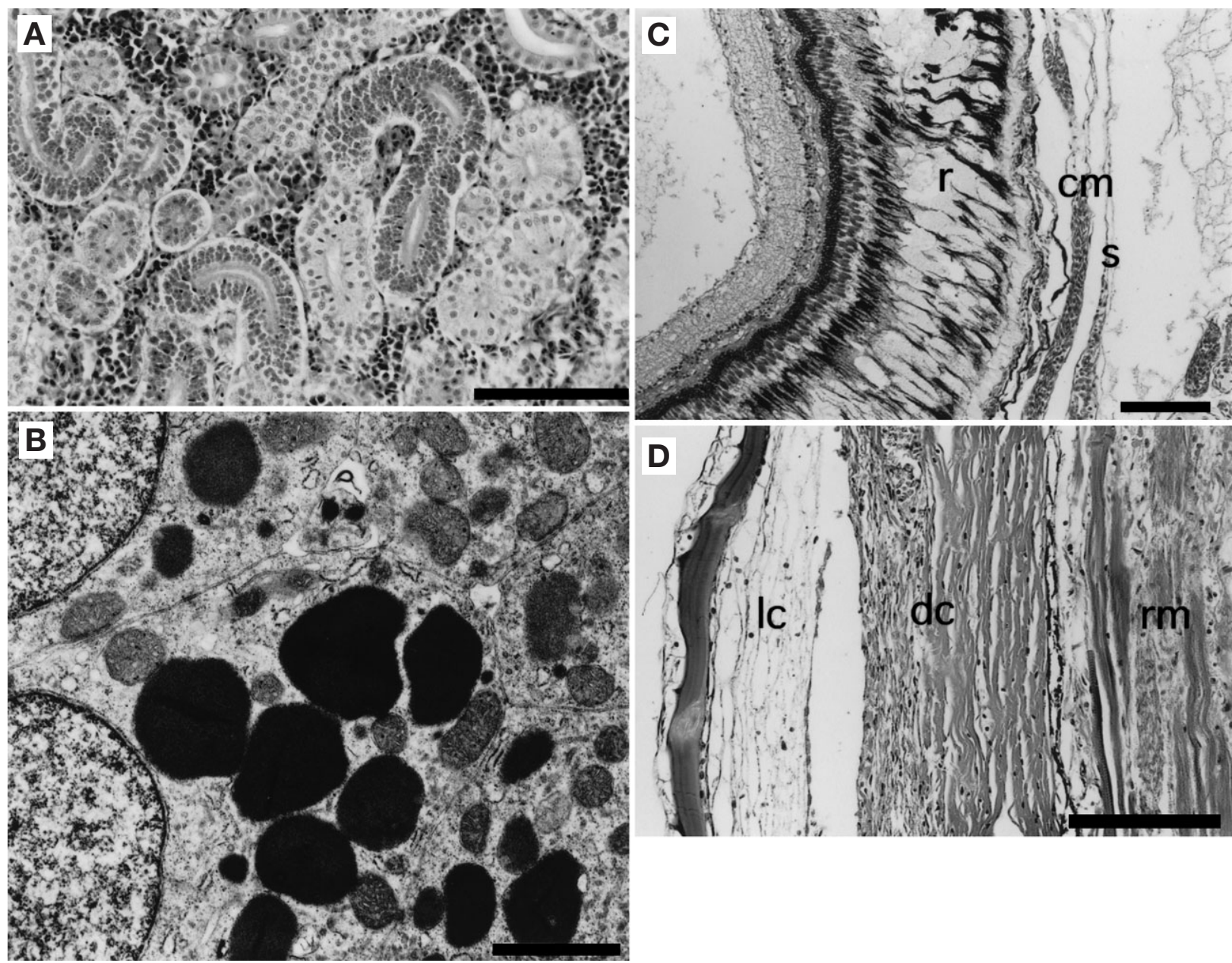

Fig. 7. Cyprinus carpio koi. (A,B) Kidney of moribund fish from the later period. (A) Renal tubular epithelial cells displaying hyaline droplet degeneration. H\&E. Scale bar $=100 \mu \mathrm{m}$. (B) Electron micrograph of tubular cells showing hyaline droplets. Mitochondria are degenerated and replaced with electron-dense bodies. Scale bar $=2000 \mathrm{~nm}$. (C) Sunken eye. The pigment layer of the retina $(\mathrm{r})$ is edematously dilated. $\mathrm{cm}$ : choroidal membrane; s: sclera. H\&E. Scale bar $=100 \mu \mathrm{m}$. (D) Ulcerative skin. Epidermis is separated, and the underlying loose connective tissue (lc) and dense connective tissue (dc) are edematously dilated. rm: red musculature. H\&E. Scale bar $=100 \mu \mathrm{m}$

(Fig. 7B). In the hematopoietic tissue, many erythrocytes with dark-brown cytoplasm were present in blood vessels and phagocytized by endothelial cells of sinusoids.

Spleen. Here, the splenic pulp was atrophic. Many erythrocytes with dark-brown cytoplasm were present in blood vessels and phagocytized by macrophages in the splenic pulps and by ellipsoid cells in the sheathed arteries.

Eye. Sunken eyes, especially, displayed hydropsy in the retina (Fig. 7C). The space between the retina and sclera became narrow, where the tissue fluid was decreased in comparison to normal eyes.

Skin and lateral musculature. In the erosive and ulcerative lesions of the skin, the epidermis was destroyed and the loose dermal connective tissue was edematously dilated (Fig. 7D). The underlying lateral musculature displayed cloudy swelling of muscle fibers (Fig. 8A). Some lesions were invaded by bacteria in the dermis and infiltrated with inflammatory cells, although no bacterial invasion occurred in the lateral musculature. EM of affected muscle cells revealed degenerated mitochondria, showing damaged cristae and replacement of electron-dense matter within a sarcoplasm which was vacuolated and contained less glycogen than unaffected cells. Myofibrils were partially damaged (Fig. 8B).

Heart. Especially in moribund fish from the later period, cardiac muscle fibers partially showed cloudy swelling.

Intestine. No pathological changes were observed in intestinal tissues. 

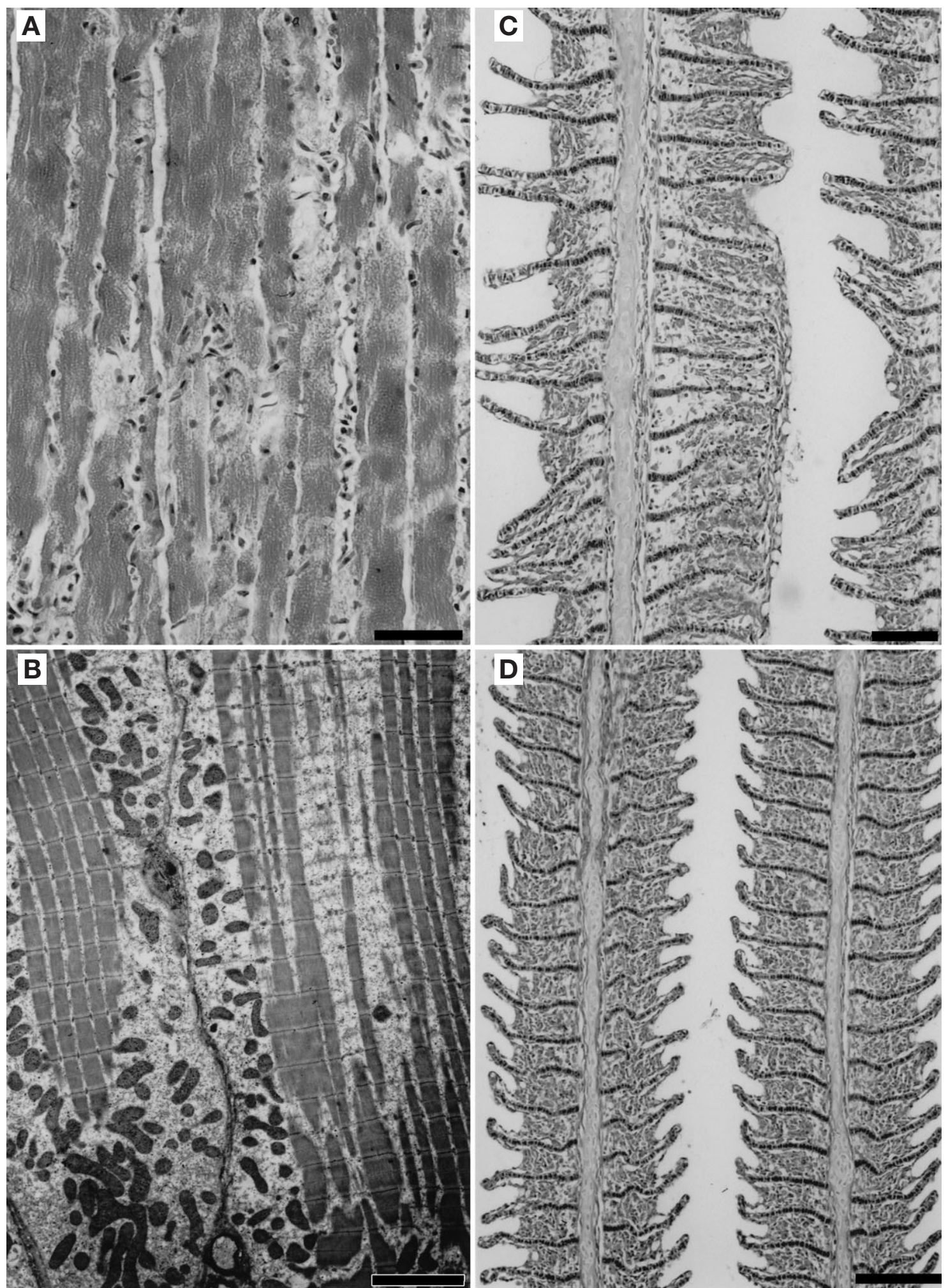

Fig. 8. Cyprinus carpio koi. (A,B) Lateral musculature. (A) Many muscle cells show cloudy appearance. H\&E. Scale bar $=50 \mu \mathrm{m}$. (B) Electron micrograph of muscle cell. Myofibrils are damaged, and many mitochondria are degenerated in the sarcoplasm which has reduced glycogen. Scale bar $=4800 \mathrm{~nm}$. (C) Gill filaments of surviving fish from fresh water. Hyperplasia of interlamellar epithelia partially extended to the tips of lamellae followed by lamellar fusion. In many lamellae, respiratory epithelia do not contain enlarged cells. H\&E. Scale bar $=100 \mu \mathrm{m}$. (D) Gill filaments of surviving fish from $0.5 \%$ salt water. Epithelial hyperplasia is evident but it does not extend to the tips of lamellae. H\&E. Scale bar $=100 \mu \mathrm{m}$ 
Fish surviving in the fresh water. At the end of the experiment (Day 25), surviving fish showed thickened interlamellar epithelia, due to proliferation of epithelial cells in the gills. Epithelial growth did not usually extend to the tips of gill lamellae (Fig. 8C). There were no enlarged cells in the respiratory epithelia of lamellae. Hepatocytes and renal tubular cells did not show cloudy swelling or hyaline droplet degeneration. Hemosiderin pigments were deposited in macrophages in splenic pulps and hematopoietic tissues.

Fish surviving in $0.5 \%$ salt water. No dead fish occurred in this group, although large numbers of gill filaments displayed growth of interlamellar epithelia (Fig. 8D). No pathological changes were observed in other visceral organs.

\section{PCR assay}

The PCR assay using a primer set (CEV-F1 and CEVR1) derived an amplicon (548 bp) from samples of gill tissue and erosive skin of moribund fish, while no amplicon was derived from samples of liver and kidney or from samples of gill tissue from surviving fish in $0.5 \%$ salt water (Fig. 9). Nested PCR using a primer set (CEV-F2 and CEV-R2) amplified 181 bp DNA fragments from samples of gill tissue from moribund fish.

\section{DISCUSSION}

Histopathology, electron microscopy and PCR assay revealed CEV (a pox-like virus) infecting respiratory epithelial cells of gill lamellae and epidermal cells in

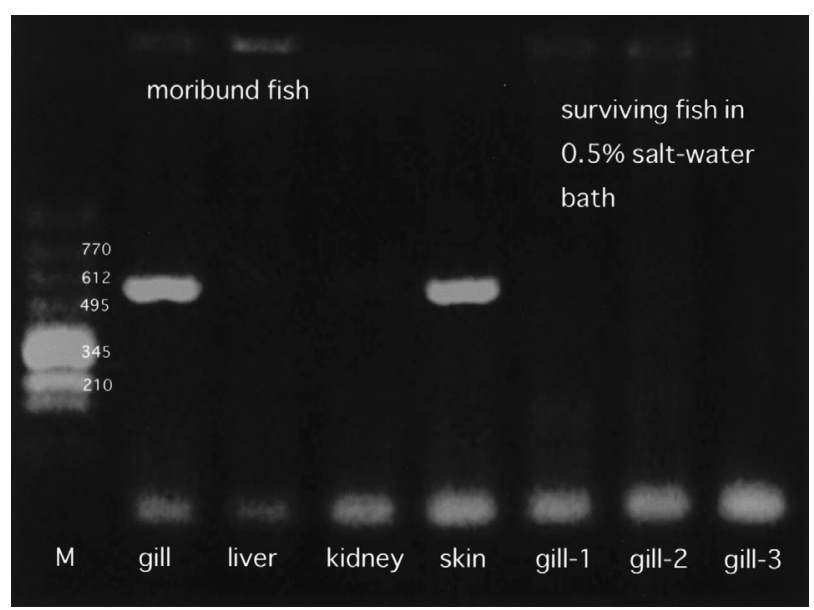

Fig. 9. Cyprinus carpio koi. PCR amplification from samples of gill, liver, kidney and erosive skin of moribund fish, and gills of surviving fish from the $0.5 \%$ salt-water bath. PCR, using a primer set of CEV-F1 and CEV-R1, produced a DNA fragment sized 548 bp. M: øX174/Hinc II digest fish suffered from KSD. CEV infection causes viral edema of carp (VEC) in early stage juvenile koi nourished in earthen ponds in June and July (Hosoya \& Suzuki 1976, Murakami et al. 1976, 1977, Ono et al. 1986). Juveniles suffering from VEC display anasarca and sunken eyes; death follows within a few days. Diseased juveniles never lie on the bottom of the pond, but lethargically congregated just under the water surface. They have swollen gills with respiratory epithelial cells infected with CEV.

CEV was determined to infect respiratory epithelial cells by artificial infection using a filtrate from gills of diseased juveniles (Ono et al. 1986, Oyamatsu et al. 1997a). Most pathological signs of VEC and KSD are the same; the differences in clinical signs appear to be dependent upon the age or the growth of fish. Therefore, in the present study, we did not perform the infection experiment using a gill homogenate from fish with KSD. In KSD, the pox-like virus (here KSDV) markedly infected respiratory epithelial cells of gill lamellae. Cellular proliferation of interlamellar epithelia removed KSDV-infected cells from gill lamellae and replaced them. This occurred so markedly that interlamellar epithelia were extensively thickened, resulting in clubbing of gill filaments. Similar compensatory removal or replacement of damaged cells has been observed for Ichthyobodo necator (Miyazaki et al. 1986), Chilodnella cyprini (T. Miyazaki unpubl data), Flavobacterium columnare (= Chondrococcus columnaris) (Kubota et al. 1982b) and koi herpesvirus (KHV) (Hedrick et al. 2000). Severe damage to the respiratory epithelia led to hypoxia that was evidenced by mitochondrial degeneration in hepatocytes and muscle cells of the lateral musculature, resulting in disturbances of energy generation within the cells. Therefore, diseased fish lost kinetic activity, displaying lethargy or sleepy behavior, and died of anoxia.

PCR assay of the erosive skin indicated that KSDV also infected epidermal cells. The epidermal damage induced hydropsy in the underlying dermis.

Why were fish held in fresh water affected with KSD, while those held in $0.5 \%$ salt water were spared the disease? In the former group, diseased fish displayed methemoglobinemia, which is known to occur in fish when nitrite is increased in fresh water (Kubota et al. 1981, 1982a, Wakabayashi 1996). Although in the present study we did not check the nitrite concentration of the water, onset of methemoglobinemia was evidence that it was high. This factor stressed the fish, allowing KSDV propagation. On the other hand, the latter group displayed hyperplastic epithelia of gill filaments, which proved that KSDV had infected respiratory epithelial cells of gill lamellae. Since salt is known to reduce the toxicity of nitrite (Wakabayashi 1996), fish suffered only slight methemoglobinemia in $0.5 \%$ salt water. 
It is well known that a $0.5 \%$ salt-water bath is effective in removing protozoan parasites from the gills and body surface of fish. The same solution also appears to remove KSDV-infected cells by causing osmotic damage, thus protecting diseased fish from severe respiratory symptoms.

EM of KSDV-infected cells revealed particles of a pox-like virus in the cytoplasm. These cells were hypertrophied with well developed organelles and maintained fine desmosomes which prevented the infected cell from separating from neighboring cells. This benefits the virus, since if infected cells were necrotic and separated from fish, virions would fail to mature. In the case of KSDV, immature virus particles were seen beside inclusions; therefore, the inclusions contained KSDV DNA. The maturing virions appeared beside or among Golgi apparatuses releasing many vesicles. Poxviruses are known to acquire structural proteins from Golgi apparatuses (Regenmortel et al. 2000). Our observations appear to indicate that KSDV also acquires structural proteins from Golgi apparatuses.

In visceral organs, it was difficult to find KSDVinfected cells, and PCR assays of the liver and kidney were negative. Thus, KSDV never infected cells of visceral organs, unlike KHV (Hedrick et al. 2000), although both KHV and KSDV severely infect respiratory epithelial cells of gill lamellae and cause mass mortality. Comparative histopathology between KHVinfection and KSD will be revealed in further studies.

Surviving fish in the $0.5 \%$ salt water showed negative results in PCR assay using DNA extract of gill tissues. This result determined that long-term bathing with the $0.5 \%$ salt water was efficacious against KSD. Based on long experience, Japanese koi farmers understand that it is worthwhile treating their commercially valuable koi with a $0.5 \%$ salt-water bath before domestic sale and exportation. When koi are imported from elsewhere, they must be held in a $0.5 \%$ salt-water bath for at least $4 \mathrm{wk}$ to prevent introduction of KSDV.

Editorial responsibility: Jo-Ann Leong,

Kaneohe, Hawaii, USA

\section{LITERATURE CITED}

Hedrick RP, Gilad O, Yun S, Spangenberg JV and 5 others (2000) A herpesvirus associated with mass mortality of juvenile and adult koi, a strain of common carp. J Aquat Anim Health 12:44-57

Hosoya H, Suzuki M (1976) Effect of $\mathrm{NaCl}$ solution bath on a disease of juvenile colorcarp accompanied by mass mortality, arising at the rainy season. Rep Niigata Pre Inland Fish Exp Station 4:69-71 (In Japanese)

Kubota SS, Amano H, Ichioka M, Miyazaki T, Niwa M (1981) Methemoglobinemia in Japanese eel. Bull Fac Fish Mie Univ 8:149-161 (in Japanese with English abstract)

Kubota SS, Amano H, Miyazaki T, Kamiya N, Ichioka M, (1982a) Studies on experimentally occurred methemoglobinemia in Japanese eel. Bull Fac Fish Mie Univ 9:135-153 (in Japanese with English abstract)

Kubota SS, Miyazaki T, Egusa S (1982b) Color atlas of fish histopathology, Vol 1. Shin-suisan-shinbunsha, Tokyo

Miyazaki T, Kubota SS, Kamitani K (1986) A histopathological study of ichthyobodosis of carp. Fish Pathol 21:209-210 (in Japanese)

Murakami Y, Shitanaka M, Toshida S, Matsuzato T (1976) Studies on mass mortality of juvenile carp: about mass mortality showing edema. Bull Hiroshima Fresh Water Fish Exp Station 19-33 (in Japanese)

Murakami Y, Shitanaka M, Toshida S, Matsuzato T (1977) Studies on mass mortality of juvenile carp-II. About mass mortality showing edema. Bull Hiroshima Fresh Water Fish Exp Station 19-36 (in Japanese)

Ono S, Nagai A, Sugai N (1986) A histopathological study on juvenile colorcarp, Cyprinus carpio, showing edema. Fish Pathol 21:167-175

Oyamatsu T, Hata N, Yamada K, Sano T, Fukuda H (1997a) An etiological study on mass mortality of cultured colorcarp juveniles showing edemas. Fish Pathol 32:81-88

Oyamatsu T, Matoyaka H, Yamamoto K, Fukuda H (1997b) A trial for the detection of carp edema virus by using polymerase chain reaction. Suisanzoshoku 45:247-251

Regenmortel MHV, Fauquet CM, Bishop DHL, Carstens EB and 7 others (2000) Virus taxonomy, 7th edn. Academic Press, New York

Wakabayashi H (1996) Diseases due to environmental factors and stress. In: Muroga K, Egusa S (eds) Introduction of fish diseases. Kouseisha-Kouseikaku, Tokyo, p 109-120 (in Japanese)

Submitted: October 1, 2004; Accepted: December 6, 2004

Proofs received from author(s): June 28, 2005 